\title{
Psychological Portrait of a Person with Virtual Addition
}

\author{
E.Yu. Shpakovskaya \\ Magnitogorsk state technical University \\ in honour of G.I. Nosov \\ Magnitogorsk, Russia
}

\author{
D.A. Khabibulin \\ Magnitogorsk state technical University \\ in honour of G.I. Nosov \\ Magnitogorsk, Russia \\ habibulin-denis@mail.ru
}

\author{
V.V. Churilov \\ Magnitogorsk state technical University \\ in honour of G.I. Nosov \\ Magnitogorsk, Russia
}

\begin{abstract}
The problem of a person with signs of virtual addiction is considered. It is revealed that such individuals are characterized by insufficient openness, weak readiness to change their own behaviour and environment, difficulties in selfacceptance, superficial communication combined with avoidance of self-revealization and deep trust, ambivalence in accepting someone's opinion, externalities, emotional and communicative barriers, reduced personal adaptive potential. There are the signs of social frustration, unwillingness to cope with some difficult life circumstances, low stress resistance. When solving problems, virtual addicts resort to strategies of escapism, confrontation, seeking social support, distancing and avoiding the problem, low self-control and responsibility.
\end{abstract}

Keywords-virtual addiction, social frustration, confrontation, self-control, virtuality

\section{INTRODUCTION}

The development of today's modern society is impossible without the use of information technology. Easy access to Internet resources is attractive for users of any age. The Internet can be described as a kind of subculture with its own specific characteristics such as: psychological features of the environment and users, their own slang, internal hierarchy, social norms and sanctions, and much more. The Internet brings together large groups of people with certain interests, shapes interpersonal relationships, affects the human psyche. The advent of social networks and specialized electronic gadgets has significantly increased the users' involvement in the process of virtual communication and created the prerequisites for forming addictions.

The extent of fascination with the opportunities within the virtual environment and various gadgets as a means of gaining access to this environment is increasing recently and causes the development of different forms of addictive behaviour. Real emotional connection with people is often replaced by the virtual, formalized and ritualized communication, and communication skills start regressing or do not receive incentives to develop. Virtual addiction, in turn, is a negative factor in the development of social maladjustment [1].

In today's world, virtual addiction affects not only children and adolescents but also adults. Specific signs of virtual addiction are manifested in cognitive, emotional, behavioural and physiological spheres.
Since the beginning of the 1990s, this issue has been under active research not only by foreign but also by domestic psychologists who study the following aspects: "the problem of computer addiction, its influence on the essence of virtual relationships, the study of identity among the network users and the processes of self-presentation in the network, psychological aspects of communicative processes in the network" $[2,3,4,5]$.

Every year the intensity of research on the phenomenon of virtual reality is increasing parallel to the growth in the number of people who use a variety of means of Internet access and carry out activities varying in content and intensity within the network. Currently, a sufficient number of works is devoted to "the study of psychological characteristics of human-computer interaction" [6, 7, 8, 9]. This type of addiction is one of the means of addictive implementation, characteristic for individuals with specific features that contribute to forming an addicted individual, or addictive implementation via the Internet into an already formed addict $[9,10]$.

Thus, "computer addiction is considered by many researchers as a form of information dependency (K. Yang), as a positive information screen dependency (A.Yu. Akopov) and as a gaming addiction (gambling) (E.V. Zmanovskaya). And M.S. Ivanov views computer addiction as a kind of deviant behaviour and draws an analogy with the psychological aspects of other kinds of addictions". Currently, the concept of "Internet addiction" is defined as an obsessive desire to log on to the Internet, while off-line, and the inability to $\log$ out of the Internet, while on-line [11].

The main problem with the above-mentioned definitions of this addiction is their incoherence with the co-morbid states; they do not identify core and additional criteria, do not determine the time spent in the network and the boundary between the norm and pathology. But, according to Yurieva L.N., "...they have an indication of the etiological factor (a computer or a gadget), but no subsequent theoretical interpretation of the issue" [2].

According to the cognitive behavioural model proposed by Davis for Internet addiction, there exist the following categories: "specific pathological Internet use and generalized pathological Internet use" [12]. A specific use involves the activation of already existing varieties of computer addictions like addiction to gambling or pornographic sites, and generalized ones, i.e. to all types of computer technologies 
(chats, social networks, instant messengers and other varieties).

Davis supplemented the definition by Kimberly Young, highlighting the core content of addiction; he showed that excessive use of the Internet activates an existing pathology or can act as a separate type of addiction.

The third term - Internet-dependent behaviour - was introduced by Alex Hall and Jeffrey Parsonsos. They agree that excessive use of the Internet can harm in many areas: behavioural, cognitive and affective, that is, strongly affect the state of human health, but they do not support the pathological etiology of this problem [11]. In contrast to the two abovementioned definitions, many scientists "represent the excessive use of the Internet as a "benign" disorder, seen as a compensation for the lack of real-life events" [11].

L.N. Yuryeva and T.Yu. Bolbot distinguish five types of addiction:

- compulsive surfing (an aimless journey through the network, search for various information);

- pathological attachment to Internet-mediated gambling (casino, lottery sites), online stock trading and auctions or eshopping;

- addiction to social Internet applications, i.e. communication in various messengers, group games, social networks which often leads to substituting real-life family and friends with virtual ones (e.g.: virtual dating, etc.);

- pathological dedication to pornographic sites (the addiction to "cybersex");

- obsessive addiction to computer use - a passion for computer games and programming [2].

G.V. Starshenbaum describes the factors of virtual reality that create psychological prerequisites for addiction "... total saturation of various analysers: visual, auditory and kinesthetic, and thus rivalling the true reality. The boundary between them is blurred due to actions aimed at the computer itself and surrounding objects. In addition, using a computer is associated with additional emotional stress due to frequent disruptions connected with the work specificity, computer management or imperfection of existing technical devices" [13].

Rapid life in the network easily replaces the real-time existence: All joys, excitement, quarrels in the network are easier to bear but happen more often than in real life. "The Internet replaces real life. This is important for those people who, for various reasons, have problems in their interpersonal relationships" [13], and the network provides them with a convenient opportunity to search for a new virtual interlocutor that meets any criteria. It should be noted that the person interviewed can be changed at any convenient time.

The idea of virtuality is becoming increasingly recognized, and the social need for new ways of explaining the world essence and managing it is becoming acuter every year. In psychology, a special type of psychic states, existing only at a specific time, has been described. This type of state is called virtual state.
The virtual environment, in our opinion, has several characteristics that make "living" and activity within the given environment most emotionally appealing:

- anonymous interpersonal and intragroup interactions with violation of social norms without achieving the appropriate sanctions;

- the possibility of modelling self-presentation and using compensation as a psychological protection tool;

-manageability of unwanted contacts and interactions without serious consequences for the personality and integrity of the I-concept;

- fascination with virtual reality, for example, within a game;

- availability of algorithmic and predictable achievement of goals such as gaming;

- the implementation of affiliative needs, for example, through likes and feedbacks in social networks;

- the realization of the need in different types of power (rewards, punishments; expert, reference or information power, etc.);

- satisfaction of information needs through search and analytical activity;

- the possibility of receiving tangible rewards;

- creativity, fantasy, going beyond the routine and available opportunities, etc.;

- regression of communication to its archaic forms (simplification of the forms of information transfer, the symbolism of emotional, cognitive and behavioural components, e.g., in smiles).

All of the foregoing has served as a basis for choosing the objective of the empirical part of our study: the analysis of psychological features of individuals with virtual addiction.

An empirical study was conducted during 2017.

The experimental sample was of random character and amounted to 1823 respondents aged from 17 to 56 , and 301 individuals out of the total number of respondents $(16.5 \%)$ were over 25. The gender composition of the sample: 778 men, 1045 women.

Methods and techniques of research:

- The survey of virtual users.

- The test to determine Internet addiction by K. Yang.

- Multilevel personal questionnaire "Adaptability" ("MPQAM") by A.G. Maklakov, S.V. Chermenin.

-The technique of diagnosing socio-psychological adaptation ("SPA") (by K. Rogers and R. Diamond) (modification by A. K. Osnitsky).

- The technique of diagnosing emotional barriers in interpersonal communication by B.V. Boyko.

- The technique of diagnosing the level of social frustration by L.I. Wasserman (modification by V.V. Boyko).

-The technique "Coping-test" (by R. Lazarus, S. Folkman).

To assess statistically significant differences between the groups of subjects we used the mathematical method of analysing the Student's t-test, and to assess the compliance with regular distribution we used the Kolmogorov-Smirnov test. 


\section{RESUlTS AND DiSCUSSION}

At the first stage of the study, 1246 respondents underwent the test, filling the electronic test form (the links to the test form were placed on the Internet, namely: social networks (vk.com and ok.ru accumulate a total audience of more than 50 million people a day); thematic networks (psychological forums, the site 'психологическая-лаборатория.рф'; entertainment sites ('yaplakal.com' accumulates an audience of more than 10 million people a day).

At the second stage of the empirical study, we carried out a full-time testing of 577 respondents who answered questionnaires in a traditional paper form.

In the third stage the complex mathematical data processing, their description and analysis were carried out.

In order to achieve the objectives of the study we formed two samples:

1. a group of the subjects (214 people) having signs of virtual addiction;

2. group of subjects ( 853 people) with no signs of virtual addiction.

The basis for sampling was the results of surveying the subjects (tab. I) and the results of the test to determine Internet addiction (K. Yang) (tab. II).

TABLE I. SUMMARY OF RESULTS OF QUESTIONING THE RESPONDENTS

\begin{tabular}{|c|c|c|}
\hline Questions & Answer option & Share \\
\hline \multirow{3}{*}{$\begin{array}{l}\text { For what purposes } \\
\text { do You use a } \\
\text { computer? }\end{array}$} & Mostly for entertainment & $18.64 \%$ \\
\hline & $\begin{array}{l}\text { Equally for work/studies and } \\
\text { entertainment }\end{array}$ & $52.03 \%$ \\
\hline & Mostly for work/studies & $29.34 \%$ \\
\hline \multirow{5}{*}{$\begin{array}{l}\text { Time spent on the } \\
\text { Internet }\end{array}$} & less than an hour & $2.59 \%$ \\
\hline & from 1 to 3 hours & $20.58 \%$ \\
\hline & from 3 to 5 hours & $33.06 \%$ \\
\hline & from 5 to 10 hours & $29.17 \%$ \\
\hline & more than 10 hours & $14.59 \%$ \\
\hline \multirow{5}{*}{$\begin{array}{l}\text { Time spent on } \\
\text { social networks }\end{array}$} & less than an hour & $18.30 \%$ \\
\hline & from 1 to 3 hours & $28.50 \%$ \\
\hline & from 3 to 5 hours & $21.75 \%$ \\
\hline & from 5 to 10 hours & $19.75 \%$ \\
\hline & more than 10 hours & $11.70 \%$ \\
\hline \multirow{3}{*}{$\begin{array}{l}\text { What electronic } \\
\text { gadgets do You } \\
\text { use? }\end{array}$} & Smartphone or tablet & $59.64 \%$ \\
\hline & Smartphone and tablet & $26.26 \%$ \\
\hline & A greater number of devices & $14.1 \%$ \\
\hline \multirow[t]{4}{*}{ Occupation } & Employed & $17.5 \%$ \\
\hline & Student (school, college, university) & $68.4 \%$ \\
\hline & Study and work & $8.3 \%$ \\
\hline & Unemployed & $5.8 \%$ \\
\hline
\end{tabular}

\begin{tabular}{|c|l|c|}
\hline \multicolumn{1}{|c|}{ Questions } & \multicolumn{1}{|c|}{ Answer option } & Share \\
\hline Computer games & Play & $87.67 \%$ \\
\cline { 2 - 3 } & Do not play & $12.33 \%$ \\
\hline
\end{tabular}

TABLE II. THE RESULTS OF THE TEST TO DETERMINE INTERNET ADDICTION (BY K. YANG)

\begin{tabular}{|l|l|l|l|}
\hline Questions & $\begin{array}{c}\text { Compliance with the } \\
\text { level of a regular } \\
\text { Internet user who } \\
\text { knows how to } \\
\text { control oneself }\end{array}$ & $\begin{array}{c}\text { The presence } \\
\text { of some } \\
\text { problems } \\
\text { related to an } \\
\text { excessive } \\
\text { passion for } \\
\text { the internet }\end{array}$ & $\begin{array}{c}\text { The presence } \\
\text { of significant } \\
\text { problems } \\
\text { related to the } \\
\text { use of the } \\
\text { Internet }\end{array}$ \\
\hline $\begin{array}{l}\text { Number of } \\
\text { people }\end{array}$ & 853 & 756 & 214 \\
\hline Share, $\%$ & 46.8 & 41.47 & 11.73 \\
\hline
\end{tabular}

Analysing the data obtained through the technique of "Adaptability" ("MPQ-AM"), we can state that respondents with signs of virtual addiction showed the results indicating the severity of the average level of behavioural regulation $(\mathrm{M}=4.89, \sigma=1.73)$. It should be noted that they also had some difficulty in controlling their own behaviour and episodic manifestations of neuropsychic instability. The subjects with signs of virtual addiction also demonstrate average performance $(M=4.68, \sigma=1.69)$ according to the scale "communicative potential", which allows us to conclude that these respondents have some difficulty in establishing contacts with people, there appear some cases of conflict and aggressive behaviour towards others. Diagnostic results obtained testify the severity of the average level of moral standard according to the scale of "moral and ethical standard" $(\mathrm{m}=4.95, \sigma=2.07)$. The subjects with signs of virtual addiction generally agree with their social role but are heavily under the reference-group influence. It is worth noting that a number of respondents (about $21 \%$ ) do not agree with their social role and norms of morality offered to them. Generalized coefficient according to the technique "Adaptability" ("MPQ-AM") $(\mathrm{M}=4.84, \sigma=1.56)$ indicates satisfactory adaptation: the effectiveness of adaptation of the subjects with signs of virtual addiction often depends on external environmental conditions, they are characterized by low emotional stability, possible antisocial disruption, aggression and conflicts, they also have signs of character accentuation.

The diagnostic results of the second group of respondents with no signs of virtual addiction show the presence of indicators that they have the relatively well-formed competence of building relations with other people, etc. (according to the scale "communicative potential" (M=7.18, $\sigma=3.42)$ ). The data received according to the scale "moral and moral standard" $(\mathrm{M}=6.86, \sigma=2.71)$ illustrate that subjects without signs of virtual-addiction aspire to observe moral norms of conduct and conform to social rules. The presence of relatively high indicators according to the scale of "behavioural regulation" $(\mathrm{M}=7.31, \sigma=3.52)$ indicates the ability of subjects with no signs of virtual addiction to regulate their own behaviour. Interpretation of the generalized coefficient according to the technique "Adaptability" ("MPQ-AM") 
$(\mathrm{M}=7.22, \sigma=2.74)$ allows to assert that subjects with no signs of virtual addiction refer to the people undergoing optimal adaptation, i.e., they are characterized by ease of adaptation to changing conditions, painless entry into a new team, the ability to adequately assess the situation and change their own behavioural strategy, emotional stability and proneness to conflict.

To statistically compare the two investigated groups of respondents we implemented mathematical analysis using a computer statistical analysis program IBM SPSS Statistics-24. The method the Student's t-test was involved in calculations. The mathematical analysis showed statistically significant differences on the scales: "Behavioural regulation" $(\mathrm{t}=2.41$; $\mathrm{p} \leq 0.05=1.96), \quad$ "Communicative potential" $\quad(\mathrm{t}=2.85$; $\mathrm{p} \leq 0.01=2.57), \quad$ "Moral standard" $\quad(\mathrm{t}=3.04 ; \mathrm{p} \leq 0.01=2.57)$, "Personal adaptive potential" $(\mathrm{t}=2.87 ; \mathrm{p} \leq 0.01=2.57)$. Thus, it is possible to assert that subjects with signs of virtual addiction are characterized by reduced behavioural regulation, less communicative potential, insufficient moral standards and, as a result, reduced personal adaptive potential, in comparison with the subjects demonstrating no signs of virtual addiction.

Analysing the results of testing through the technique of diagnosing socio-psychological adaptation (SPA), it is worth noting that respondents with signs of virtual addiction show low indicators on scales of adaptability $(M=78.7, \sigma=15.8)$, selfacceptance $(\mathrm{M}=31.5, \sigma=7.56)$, acceptance of other people $(\mathrm{M}=17.4, \sigma=5.37)$, internality $(\mathrm{M}=32.9, \sigma=6.84)$, significant levels of escapism $(\mathrm{M}=16.7, \sigma=4.79)$ and emotional discomfort $(\mathrm{M}=21.8, \sigma=6.35)$. The diagnostics data characterize the subjects with signs of virtual addiction as people with insufficient openness to real-life practice, weak readiness to change their own behaviour and environment; experiencing the complexity of self-reflection and reflection. A similar tendency is evident in relation to other people: the contacts are of a superficial character in combination with the avoidance of selfrevealization and intimate trust relationship, at the same time, the opinion of others remains important for them, although most respondents are afraid of these opinions. When trying to solve problems, the subjects with signs of virtual addiction resort to the strategy of escapism, i.e. prefer to cope with the challenges through virtual means that exist only subjectively. The distinctive features of the virtual addicts usually include anxiety, stress and emotional discomfort, they demonstrate a certain degree of submissiveness, the lack of their own opinions on certain issues, their own beliefs and rules.

According to the results of diagnosing the subjects with no signs of virtual addiction we can describe them as quite adaptive $(M=123.1, \sigma=24.28)$, tending to solve tasks and to achieve their own goals, ambiguously assessing their personality and behavioural characteristics, not always able to establish emotionally warm and friendly relations, to tolerate other people; their emotional reactions are quite varied and usually depend on the situation which they face. They also demonstrate the escapism strategy, but to a lesser extent $(\mathrm{M}=$ $10.3, \sigma=3.72$ ) when facing life-altering issues; they are not always independent in shaping their own opinion and tend to come under the influence of other people.
The mathematical comparison of the empirical results of both groups showed statistically significant differences on the scales: adaptability $(\mathrm{t}=3.67 ; \mathrm{p} \leq 0.01=2.57)$, self-acceptance $(\mathrm{t}=2.94 ; \mathrm{p} \leq 0.01=2.57)$, acceptance of other people $(\mathrm{t}=3.13$; $\mathrm{p} \leq 0.01=2.57)$, internality $(\mathrm{t}=3.38 ; \mathrm{p} \leq 0.01=2.57)$, escapism $(\mathrm{t}=2.17 ; \mathrm{p} \leq 0.05=1.96)$. Thus, the respondents with signs of virtual addiction are characterized by more obvious inadaptability, reduced self-acceptance and acceptance of others, an externality, a tendency to escape from reality, in comparison with the subjects demonstrating no signs of virtual addiction.

Analysis of the results through the technique "Diagnostics of emotional barriers in interpersonal communication" showed that the central communicative problems of Internet addicts include reluctance to get emotionally closer to people $(\mathrm{M}=13.6$, $\sigma=4.13$ ), inflexibility, underdevelopment and inexpressiveness of emotions $(\mathrm{M}=12.8, \sigma=4.78)$, as well there are certain difficulties in managing their emotions and measuring them $(\mathrm{M}=10.6, \sigma=3.82)$, expressing emotions in an adequate manner $(\mathrm{M}=10.3, \sigma=3.87)$, coping with negative emotions $(\mathrm{M}=11.9$, $\sigma=4.08)$.

Sampling respondents with no signs of virtual addiction is characterized by the desire to establish emotionally-rich relationships with other people $(\mathrm{M}=6.2, \sigma=2.25)$, although they sometimes have problems with regulation $(\mathrm{M}=8.4, \sigma=3.64)$, flexibility, expressiveness $(M=10.4, \sigma=3.77)$, adequacy when manifesting their emotions $(\mathrm{M}=7.7, \quad \sigma=2.96)$ with a predominance of positive emotional background $(\mathrm{M}=4.8$, $\sigma=1.83)$.

Comparison of two samples by using Student's t-test showed the following statistically significant differences on scales: "Reluctance to get emotionally closer to people" ( $t=4.23$ at $\quad \mathrm{p} \leq 0.01=2.57)$, "Inflexibility, underdevelopment, inexpressiveness of emotions" $(\mathrm{t}=3.14$ at $\mathrm{p} \leq 0.01=2.57)$, "Dominance of negative emotions" $(\mathrm{t}=3.32$ at $\mathrm{p} \leq 0.01=2.57)$.

Thus, the virtually addictive subjects have more significant communication barriers manifesting itself in emotional detachment and indifference towards others, emotional poverty and rigidity, dysphoric states in a situation of a communicative contact. The revealed features can serve as a destructive condition that reduces the success of social and psychological adaptation. On the other hand, the representatives of this sample can use the virtual environment as a compensation for their failure. Active users of electronic devices accessing the Internet substitute true emotional manifestations with their symbolic representations that gradually narrow the range of emotions. The dominant negative emotional background can be associated with outbreaks of irritation, tension and negative experiences in the situation of network unavailability.

The results obtained through the method "Diagnostics of social frustration" indicate that a group of subjects with signs of virtual addiction demonstrates considerable social frustration. They are not able to cope with certain difficulties, are often indifferent to what is happening around, get irritated easily; often experience stress, dissatisfaction and irritation in these situations. The subjects without signs of virtual addiction showed the average level of social frustration in the basic aspects of life. They are characterized by certain apathy and a 
situational state of helplessness when facing difficult life circumstances. The marked differences are confirmed by statistically significant coefficients of the Student's t-test $(\mathrm{t}=$ 2.22 at $\mathrm{p} \leq 0.05=1.96$ ). It should be noted that the state of frustration among the subjects with signs of virtual addiction manifests itself not only in real life but within the network for a number of reasons (because of the redundancy of information, not constant full access to the computer, a failure to obtain emotional support in the network, the dissonance of opinions to the issues discussed in online forums, social networks and chat rooms).

The results of the diagnostics through the technique "Coping-test" showed the following peculiarities of coping behaviour among the subjects with signs of virtual addiction: they are prone to confrontation $(\mathrm{M}=10.4, \sigma=2.87)$, distancing $(\mathrm{M}=12.2, \sigma=3.17)$, seeking social support $(\mathrm{M}=12.3, \sigma=3.85)$, low level of self-control $(\mathrm{M}=6.8, \sigma=2.36)$, insufficient acceptance of responsibility $(\mathrm{M}=6.2, \quad \sigma=1.98)$, escapeavoidance $(\mathrm{M}=12.1, \sigma=3.65)$, moderate severity of copingplanning the solutions of the problems $(M=9.3, \sigma=3.98)$ and positive reappraisal $(\mathrm{M}=8.6, \sigma=2.82)$. The obtained results indicate that respondents with signs of virtual addiction are ready to take risks and confidently act in the situations simple enough; but when they face serious difficulties, they either show open aggression or, conversely, distract from the situation without making any efforts to alter the situation. They have some difficulties in controlling themselves and their emotions, they tend to hasty, ill-conceived actions. The subjects with signs of virtual addiction need support, often satisfying it in virtual reality. In case of real problems, the respondents from this group avoid taking responsibility for both the appearing problem and its solution; give the impression of spontaneous solutions of existing difficulties for themselves. Coping skills of planning problem-solving and positive reappraisal of the situation are applied quite spontaneously and situationally.

\section{CONCLUSION}

The identified psychological characteristics of individuals with virtual addiction and their analysis showed the presence of peculiar traits that can be described as a generalized psychological portrait. A person with virtual addiction is characterized by a lack of openness in social contacts, low willingness to change the stereotypes of their own behaviour, the unwillingness to actively change the environment and to manifest their subjectivity outside the virtual space, escapism. There are certain difficulties in self-acceptance, avoidance of self-revealization and intimate trust relationships, strong emotional and communicative barriers. The virtual addict differs in externality, unwillingness to cope with some difficult life circumstances, reduced personal adaptive potential. There are found the signs of reduced stress resistance, a tendency to social frustration and the use of inefficient coping: confrontation, seeking social support, distancing and avoiding the problem, low self-control and responsibility. Virtual addicts do not adequately rely on moral beliefs when regulating their social behaviour.

The conducted research does not reveal the mechanism and dynamics of forming virtual addiction and does not show determinative factors of its development. The further in-depth study of the issue may relate to the identification and investigation of the predisposition factors of virtual addiction and personal resources that prevent the addictive behaviour.

\section{REFERENCES}

[1] O. Seemann, V.D. Seemann, R. Boerner, and et al, "Psyber-therapy on the Internet and its implications for psychiatry, psychotherapy, and psychosomatics," in European journal of medical research, vol. 3(12), pp. 571-576, 1998.

[2] L.N. Yuryeva, and T.Yu. Bolbot, "Computer addiction: formation, diagnostics, correction and prevention," Dnepropetrovsk: Porogi, 2006, $196 \mathrm{p}$.

[3] J.P. Charlton, "A factor-analytic investigation of computer addiction and engagement," in British Journal of Psychology, vol. 93 (Pt. 3), pp. 329344, 2002.

[4] M. Griffiths, "Internet addiction: Fact or fiction?" in Psychologist, vol. 12(5), pp. 246-250, 1999.

[5] A. Ibanez, C. Blanco, I.P. de Castro, and et al, "Genetics of pathological gambling," J. of Gambling Studies, vol. 19(1), pp. 11-22, 2003.

[6] J. Billieux, P. Maurage, O. Lopez-Fernandez, D.J. Kuss, and M.D. Griffiths, "Can disordered mobile phone use be considered a behavioral addiction? An update on current evidence and a comprehensive model for future research," in Current Addiction Reports, vol. 2, no. 2, pp.156$162,2015$.

[7] V.L. Malygin, N.S. Khomeriki, E.A. Smirnova, and A.A. Antonenko, "Internet addictive behavior," in Neuroscience And Behavioral Physiology, vol. 43 (Pt 1), pp.100-105, 2013.

[8] N.A. Shapira, T.D. Goldsmith, P.E. Keck, and et al, "Psychiatric features of individuals with problematic Internet use," in Journal of Affective Disorders, vol. 57(1-3), pp. 267-272, 2000.

[9] A.E. Voiskunskii, "Current problems in internet addiction," in Psikhol. Zh., vol. 25, no. 1, pp. 90-100, 2004.

[10] M. D. Griffiths, "Internet addiction: does it really exist?" in: Psychology and the Internet: Intrapersonal, Interpersonal, and Transpersonal Applications, J. Gackenbach Academic Press, New York, pp. 61-75, 1998.

[11] H.J. Shaffer, M.N. Hall, and J. van der Bilt, "Computer addiction: A critical consideration," in American journal of Orthopsychiatry, vol. 70(2), pp. 162-168, 2000.

[12] R.A. Davis, "A cognitive-behavioral model of pathological Internet use," in Computers in Human Behavior, vol. 17(2), pp. 187-195, 2001.

[13] G. N. Starshenbaum, "Addictology: psychology and psychotherapy of addictions," Moscow: Cogito-Centre, 2006, pp. 153-157. 